\title{
Extraction of bioactive compounds from Psidium guajava leaves and its utilization in preparation of jellies
}

\author{
N. S. Sampath Kumar ${ }^{1}$, Norizah Mhd Sarbon², Sandeep Singh Rana ${ }^{3}$, Anjani Devi Chintagunta ${ }^{1 *} \mathbb{D}$, S. Prathibha ${ }^{1}$, \\ Satheesh Kumar Ingilala' ${ }^{1}$ S. P. Jeevan Kumar' ${ }^{4}$ B. Sai Anvesh ${ }^{5}$ and Vijaya Ramu Dirisala ${ }^{1}$
}

\begin{abstract}
Psidium guajava L. (guava) is predominantly grown throughout the world and known for its medicinal properties in treating various diseases and disorders. The present work focuses on aqueous extraction of bioactive compounds from the guava leaf and its utilization in the formulation of jelly to improve the public health. The guava leaf extract has been used in the preparation of jelly with pectin $(1.5 \mathrm{~g})$, sugar $(28 \mathrm{~g})$ and lemon juice $(2 \mathrm{~mL})$. The prepared guava leaf extract jelly $(G J)$ and the control jelly $(C J$, without extract) were subjected to proximate, nutritional and textural analyses besides determination of antioxidant and antimicrobial activities. GJ was found to contain carbohydrate (45.78 g/100 g), protein ( $3.0 \mathrm{~g} / 100 \mathrm{~g})$, vitamin C (6.15 mg/100 g), vitamin B3 (2.90 mg/100 g) and energy (120.6 kcal). Further, the texture analysis of $\mathrm{CJ}$ and $\mathrm{GJ}$ indicated that both the jellies showed similar properties emphasizing that the addition of guava leaf extract does not bring any change in the texture properties of jelly. GJ exhibited antimicrobial activity against various bacteria ranging from 11.4 to $13.6 \mathrm{~mm}$. Similarly, GJ showed antioxidant activity of 42.38\% against DPPH radical and 33.45\% against hydroxyl radical. Mass spectroscopic analysis of aqueous extract confirmed the presence of esculin, quercetin, gallocatechin, 3-sinapoylquinic acid, gallic acid, citric acid and ellagic acid which are responsible for antioxidant and antimicrobial properties.
\end{abstract}

Keywords: Antioxidant activity, Antimicrobial activity, Bioactive compounds, Guava leaf extract, Jelly, Texture analysis

\section{Introduction}

Psidium guajava L. (guava) grows predominantly in various countries with in tropical and subtropical regions. Guava has several medicinal properties and is well known for treating dysentery, vertigo, skin problems, jaundice, cerebral ailments, diabetes etc. It is rich in phenolics, flavonoids, triterpenoids, tannins, vitamins, essential oils and sesquiterpene alcohols (Altemimi et al. 2017; Singh et al. 2019). Guava leaves mainly constitute rutin, naringenin, gallic acid, catechin, epicatechin, kaempferol, isoflavonoids, and flavonoids such as quercetin and guaijaverin that are well known for their antimicrobial,

\footnotetext{
*Correspondence: sumapriya.ch@gmail.com

1 Department of Biotechnology, Vignan's Foundation for Science, Technology and Research, Vadlamudi, Andhra Pradesh 522213, India Full list of author information is available at the end of the article
}

antioxidant and anti-inflammatory actions (GutiérrezGrijalva et al. 2018; Shaheena et al. 2019). Due to the copious benefits, guava is cultivated worldwide where, India stands in the first position with the production of 40,54,000 million tons (MT) from 2,65,000 hectares (ha) in the year 2017-18 (Horticultural Statistics at a Glance 2018).

However, due to inappropriate transportation, handling and processing, the fruit wastage is nearly $20-25 \%$ of total guava production which was reduced by processing into various value added products viz., juice, jam, jelly, wine and toffee (Kumari et al. 2017; Jacob et al. 2016). Jellies attract the attention of consumers due to their colour, smooth texture, flavour and sweet taste. Generally, jelly is prepared by boiling a clear fruit extract with sugar, citric acid, additives and pectin to give a semi-solid appearance.
Springer Open (c) The Author(s) 2021. This article is licensed under a Creative Commons Attribution 4.0 International License, which permits use, sharing, adaptation, distribution and reproduction in any medium or format, as long as you give appropriate credit to the original author(s) and the source, provide a link to the Creative Commons licence, and indicate if changes were made. The images or other third party material in this article are included in the article's Creative Commons licence, unless indicated otherwise in a credit line to the material. If material is not included in the article's Creative Commons licence and your intended use is not permitted by statutory regulation or exceeds the permitted use, you will need to obtain permission directly from the copyright holder. To view a copy of this licence, visit http://creativeco mmons.org/licenses/by/4.0/. 
The synthetic additives for colour and flavour are considered as potential carcinogenic or neurotoxic agents and hence, their usage was restricted. Concomitantly, the demand for clean label foods with natural ingredients rich in antioxidant properties has attracted the attention of consumers and food industries (Singh et al. 2019).

Keeping in view of food producer's requirements, the present work is aimed at the preparation of jellies rich in bioactive compounds. Despite of using a well studied guava fruit as an ingredient in the jelly preparation, a relatively less exploited guava leaves were employed in the present study. The aqueous extraction was performed to isolate the bioactive compounds from the guava leaves and their characterization has been carried out by Mass spectroscopy. The jellies with and without guava extract were prepared by following standard protocol and their proximate, texture and organoleptic analysis were performed to achieve the objective. The jelly prepared with guava leaf extract was considered as vehicle to promote the intake of bioactive compounds rich in antioxidant and antibacterial properties.

\section{Materials and methods}

All chemicals used for different experimental studies such as chloroform, conc. $\mathrm{H}_{2} \mathrm{SO}_{4}$, ammonium hydroxide, methanol, formic acid, acetonitrile, ampicillin, glucose, phenol red, 5,5-dimethylpyrroline- $N$-oxide (DMPO), $\mathrm{FeSO}_{4}, \mathrm{H}_{2} \mathrm{O}_{2}$ were of analytical grade procured from $\mathrm{M} / \mathrm{s}$. SD Fine, M/s. Qualigens and M/s. SRL, India. Pectin was procured from Purix India Pvt. Ltd., 2,2-diphenyl-1-picrylhydrazyl (DPPH) and Muller Hinton broth were procured from M/s. Sigma and M/s. HiMedia respectively.

\section{Sample collection and processing}

Fresh leaves of P. guajava L. (guava) were collected from the premises of Vignan's Foundation for Science, Technology and Research, Vadlamudi $\left(16.2334^{\circ} \mathrm{N}, 80.5509^{\circ}\right.$ E). The leaves were rinsed gently with double distilled water, shade dried and powdered using a blender. The powder was then passed through aluminium sieve (1 $\mathrm{mm}$ ) to get uniform particle size. Guava leaf powder was stored in an air tight container for further studies.

\section{Preparation of guava leaf extract}

The guava leaf powder $(20 \mathrm{~g})$ was boiled at $90{ }^{\circ} \mathrm{C}$ in 100 $\mathrm{mL}$ of double distilled water in sterile Erlenmeyer flask $(150 \mathrm{~mL})$ for $30 \mathrm{~min}$. The mixture was centrifuged at $4000 \mathrm{rpm}$ for $10 \mathrm{~min}$ (Biswas et al. 2013). The supernatant was separated and stored at $4{ }^{\circ} \mathrm{C}$ for further studies.

\section{Phytochemical screening of guava leaf extract}

The guava leaf extract was tested for the presence of bioactive components. A mixture containing glacial acetic acid ( $2 \mathrm{~mL}), 2$ drops of $\mathrm{FeCl}_{3}$ and $2 \mathrm{~mL}$ of conc. $\mathrm{H}_{2} \mathrm{SO}_{4}$ was mixed with aqueous extract. A brown ring at the interface confirms the presence of glycosides. For detection of saponin, the extract was taken in a measuring cylinder, diluted with distilled water and was shaken vigorously for the formation of foam (Kokate 1999). The presence of tannins and phenols were confirmed by formation of blue-green/black colour upon mixing the extract $(1 \mathrm{~mL})$ with $2 \mathrm{~mL}$ of $\mathrm{FeCl}_{3}(2 \%$, w/v) (Evans 1997). For screening terpenoids, $5 \mathrm{~mL}$ of extract was mixed with $2 \mathrm{~mL}$ of chloroform and $3 \mathrm{~mL}$ of conc. $\mathrm{H}_{2} \mathrm{SO}_{4}$ to form a layer. The presence of terpenoids is confirmed by the formation of reddish brown colour at the interface. Besides, the presence of flavonoids is confirmed by yellow fluorescence upon treating $0.5 \mathrm{~mL}$ of extract with $5 \mathrm{~mL}$ of $10 \%$ ammonium hydroxide solution (Evans 1997).

\section{Characterization of phytochemicals by mass spectroscopy}

Mass Spectroscopy is an analytical technique used for separation and identification of various components present in a mixture. Agilent 1100 LC/MS System with Chemstation Rev.A.09.01 (1206) software was used for sample processing and analysis. The extract was mixed in methanol in 1:10 ratio and $20 \mu \mathrm{L}$ of the sample was directly injected into the mobile phase $[0.1 \%$ formic acid in water (50\%) and acetonitrile (50\%)] at a flow rate of 0.5 $\mathrm{mL} / \mathrm{min}$. The electrospray ionization (ESI) was set in negative ionization mode in $60-200 \mathrm{~V}$ and capillary voltage at $4000 \mathrm{~V}$. Nitrogen is used as nebulizing gas at $350{ }^{\circ} \mathrm{C}$ and 30 psi pressure with flow rate of $8-10 \mathrm{~L} / \mathrm{min}$.

\section{Preparation of jelly and its proximate analysis}

Two types of jellies, with and without guava leaf extract was prepared by mixing pectin, sugar and lime juice as the major ingredients. In $100 \mathrm{~mL}$ of water, pectin $(1.5 \mathrm{~g})$ along with $28 \mathrm{~g}$ of sugar and guava leaf extract $(10 \%, \mathrm{v} / \mathrm{v})$ was mixed and boiled at $100{ }^{\circ} \mathrm{C}$ till the mixture was thickened. To minimize pre-gelling and hydrolysis of pectin, 2 $\mathrm{mL}$ of Citrus aurantifolia was added at the end of boiling. The mixture was cooled for the jelly formation and stored in airtight container. Further, the jellies were subjected to proximate composition (AOAC 2008) and texture analysis.

\section{Physicochemical analysis}

The total soluble solids (TSS) of samples is determined by using hand refractometer (Model- MCP Metal and PP), having range of $0-100^{\circ} \mathrm{Brix}$ (Ghosh et al. 2017). The digital pH meter (Mettler Toledo, USA) was used to measure the $\mathrm{pH}$ of the samples.Viscosity of the samples was determined by Brookfield Viscometer (Model DV1 Digital Brookfield, Middleboro, USA) at $30 \pm 0.5{ }^{\circ} \mathrm{C}$ (Keshani et al. 2012). 


\section{Texture analysis}

Texture profile of jellies was determined by using CT3 texture analyser connected to a cylindrical probe (TA4/1000, $20 \mathrm{~mm} \mathrm{~L}$ ) at pre-test speed: $2.00 \mathrm{~mm} / \mathrm{s}$, test speed: 1.00 $\mathrm{mm} / \mathrm{s}$, post-test speed: $1.00 \mathrm{~mm} / \mathrm{s}$ and load cell: 10,000 g. The total profile analysis of jellies was performed for two cycles for 5 replications. Various properties such as firmness, cohesiveness, chewiness, springiness and gumminess were determined by calibrated load cell through measuring the resistance of material against force applied by the spindle, and analyzed results were taken from the installed Texture Pro CT Software in their respective units (Ghosh et al. 2017).

\section{Determination of antibacterial activity}

Guava leaf extract was assessed for antibacterial activity against Proteus vulgaris (MTCC 744), Streptococcus mutans (MTCC 890), Bacillus subtilis (MTCC 1305) and Staphylococcus aureus (MTCC 9760) by disc diffusion method. Each strain was maintained on nutrient agar slant at $37{ }^{\circ} \mathrm{C}$ for $24 \mathrm{~h}$. The inoculum was uniformly spread over the surface of the nutrient agar plate and allowed to dry. The sterile disc $(6 \mathrm{~mm})$ was loaded with $60 \mu \mathrm{L}$ of guava leaf extract and placed on the inoculated agar plate before incubating at $37{ }^{\circ} \mathrm{C}$. The zone of inhibition obtained due to antagonistic effect of guava aqueous leaf extracts was recorded after $24 \mathrm{~h}$ of incubation. The double distilled water used for extraction and Ampicillin $(50 \mathrm{mg} / \mathrm{mL})$ was considered as negative and positive controls. The diameter of inhibitory zone was measured both vertically and horizontally and its average (in $\mathrm{mm}$ ) was considered (Guntur et al. 2018). Similarly, antibacterial activity of jelly prepared with and without guava leaf extract was also determined.

\section{Determination of antioxidant activity}

Guava leaf extract $(50 \mu \mathrm{g} / \mu \mathrm{L})$ was thoroughly dissolved in DMPO $(0.5 \mathrm{M}, 20 \mu \mathrm{L})$ mixed with $\mathrm{FeSO}_{4}(15 \mathrm{mM}$, $20 \mu \mathrm{L})$ and $\mathrm{H}_{2} \mathrm{O}_{2}(15 \mathrm{mM}, 20 \mu \mathrm{L})$ in a phosphate buffer solution ( $\mathrm{pH} 7.4$ ), and filled into a quartz tube. Radical concentration was quantified after $120 \mathrm{~s}$ in an electron spin resonance (ESR) spectrometer (Bruker, Germany). The experimental conditions employed were power 5 $\mathrm{mW}$; magnetic field $336.5 \pm 5 \mathrm{mT}$; amplitude $1 \times 1000$; modulation frequency $9.41 \mathrm{GHz}$; sweep time $30 \mathrm{~s}$ (Nazeer et al. 2013). In similar fashion, an aliquot of 50 $\mu \mathrm{g} / \mu \mathrm{L}$ guava leaf extract was added to $50 \mu \mathrm{L}$ of $\mathrm{DPPH}$ dissolved in ethanol at $60 \mu \mathrm{M}$ concentration and tested. Similar parameters were deployed for assessment of antioxidant activity of jelly prepared with and without guava leaf extract. Radical scavenging potentiality was calculated with the following equation:

$$
\text { Radical scavenging ability }(\%)=\frac{\left(\mathrm{H}_{0}-\mathrm{H}\right)}{\mathrm{H}_{0}} \times 100 \text {, }
$$

where $\mathrm{H}$ indicates relative peak height of radical signals with sample (guava leaf aqueous extract/jelly). $\mathrm{H}_{0}$ indicates relative peak height of radical signals without sample (guava leaf aqueous extract/jelly). Guava leaf extract from 25 to $125 \mu \mathrm{g} / \mu \mathrm{L}$ was evaluated to determine $50 \%$ of inhibition concentration (IC50) of DPPH radical.

\section{Sensory evaluation}

Sensory evaluation of the jelly samples were conducted through a panel of 20 members ( 8 female, 12 males, of age group 20-40) using a hedonic scale ranging from least preferred (1) to most preferred (9) (Watts et al. 1989). The products were served to all the members for examining the quality and assign score for the characteristics viz., color, taste, texture, aroma and overall acceptability. Drinking water was offered to the panelists to cleanse their pallet after tasting each jelly sample. A questionnaire was supplied to each panelist for assigning their scores (Reddy et al. 2015).

\section{Statistical analyses}

All the experiments were conducted on three replicates and data was expressed as mean \pm standard deviation. The statistical analysis was performed using IBM SPSS statistics for windows, 20.0 software (IBM Corp., Armonk, N.Y., USA).

\section{Results}

Extraction and characterization of bioactive compounds Guava leaf is known for possessing good source of bioactive compounds and in order to utilize these compounds, aqueous extract was prepared and assessed for qualitative confirmation of secondary metabolites. As shown in Table 1, glycosides, flavonoids, saponins, phenols, terpenoids and tannins were present in the extract. Further, specific confirmation and characterization of secondary metabolites present in the extract was carried out using

Table 1 Phytochemical analysis of guava leaf extracts

\begin{tabular}{lllll}
\hline Compound & Glycosides & Flavonoids & Saponins & Phenols \\
\hline Psidium guajava L. (guava) etract & + & + & + & +
\end{tabular}


Table 2 Compounds identified by mass spectroscopy and their properties

\begin{tabular}{|c|c|c|c|c|c|}
\hline Compound & Peak (m/z) & Class & Chemical name/structure & $\begin{array}{l}\text { Reported biological, } \\
\text { activities }\end{array}$ & References \\
\hline Quercetin & 293.1 & Flavonoid & $\begin{array}{l}3,3^{\prime}, 4^{\prime}, 5,7-P e n t a h y d r o x y \text { fla- } \\
\text { vone }\end{array}$ & $\begin{array}{l}\text { Antioxidant, anti-inflamma- } \\
\text { tory and anti-allergy }\end{array}$ & Sharma and Gupta (2010) \\
\hline Gallocatechin & 311.1 & Flavonoid & Flavan-3,3', $4^{\prime}, 5,5^{\prime}, 7$-hexol & Antioxidant and anti-cancer & Legeay et al. (2015) \\
\hline Esculin & 281.2 & Hydroxycoumarin & $\begin{array}{l}\text { 6-O-Beta-D-glucoside of escu- } \\
\text { letin }\end{array}$ & $\begin{array}{l}\text { Antioxidant, anticancer and a } \\
\text { metabolite }\end{array}$ & Wang et al. (2013) \\
\hline 3-Sinapoylquinic acid & 379.1 & Quinic acid derivative & $\begin{array}{l}\text { Cyclohexane ring with } \\
\text { four hydroxyl groups at } \\
\text { positions 1,3.4, and 5, and } \\
\text { carboxylic acid at position } 1\end{array}$ & Antioxidant and anti-cancer & Legeay et al. (2015) \\
\hline Ellagic acid & 341.0 & Phenolic acid & $\begin{array}{l}\text { Dilactone of hexahydroxy- } \\
\text { diphenic acid }\end{array}$ & $\begin{array}{l}\text { Antioxidant, antihepatotoxic, } \\
\text { antisteatosic, antichole- } \\
\text { static, antifibrogenic, } \\
\text { anti-hepatocarcinogenic, } \\
\text { antibacterial, and antiviral }\end{array}$ & $\begin{array}{l}\text { García-Nino and Zazueta } \\
\text { (2015) }\end{array}$ \\
\hline Gallic acid & 144.0 & Phenolic acid & Trihydroxybenzoic acid & $\begin{array}{l}\text { Antibacterial, anti-fungal, } \\
\text { antiviral, anti-inflammatory, } \\
\text { antioxidant, anticancer, } \\
\text { anti-diabetic }\end{array}$ & Nayeem et al. (2016) \\
\hline Citric acid & 191.0 & Carboxylic acid & $\begin{array}{l}\text { 2-Hydroxy-1,2,3-propanetri- } \\
\text { car-boxylic acid }\end{array}$ & $\begin{array}{l}\text { Antibacterial,calculi dissolu- } \\
\text { tion agent, anticoagulant, } \\
\text { preservative agent }\end{array}$ & $\begin{array}{l}\text { García-Nino and Zazueta } \\
\text { (2015) }\end{array}$ \\
\hline
\end{tabular}

mass spectroscopy (MS) based on the mass-to-charge ratio of ions.
Upon subjecting the extracted compounds to negative mode mass spectroscopy several peaks were observed (Fig. 1). The peaks at $\mathrm{m} / \mathrm{z} 281.2$ and 293.1 indicate the

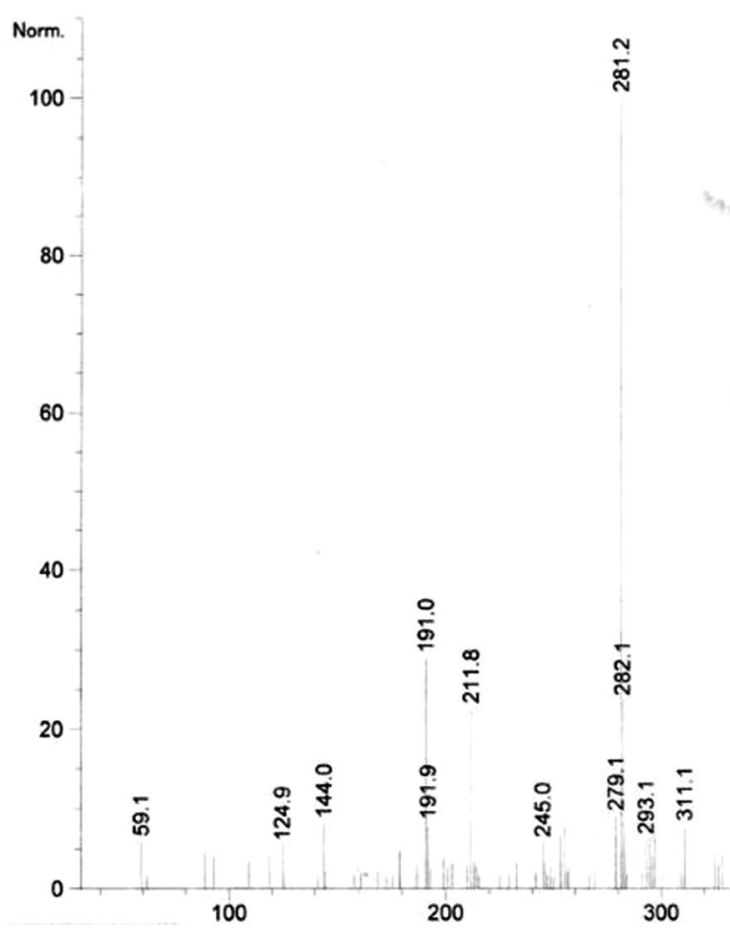

宓

Fig. 1 Liquid chromatography mass spectrometry (LC-MS) analysis of guava leaf extract 
presence of fragments of esculin $\left(\mathrm{C}_{17} \mathrm{H}_{26} \mathrm{O}_{4}\right)$ and quercetin $\left(\mathrm{C}_{15} \mathrm{H}_{10} \mathrm{O}_{7}\right)$. Further, the peak at $\mathrm{m} / \mathrm{z} 311.1$ indicates the presence of gallocatechin $\left(\mathrm{C}_{15} \mathrm{H}_{14} \mathrm{O}_{7}\right)$ in the guava extract. Moreover, the peak at $\mathrm{m} / \mathrm{z} 379.1$ represents the compounds 3-sinapoylquinic acid $\left(\mathrm{C}_{17} \mathrm{H}_{20} \mathrm{O}_{9}\right)$. Apart from these compounds, peaks at $\mathrm{m} / \mathrm{z} 144.0,191.0$ and 341.0 represent the presence of gallic acid $\left(\mathrm{C}_{7} \mathrm{H}_{6} \mathrm{O}_{5}\right)$, citric acid $\left(\mathrm{C}_{6} \mathrm{H}_{8} \mathrm{O}_{7}\right)$ and ellagic acid $\left(\mathrm{C}_{14} \mathrm{H}_{6} \mathrm{O}_{8}\right)$ respectively (Table 2).

\section{Proximate and vitamin composition of jellies}

Upon considering the demand for value added products and fortified foods, bioactive compounds extracted from guava leaf has been used in the preparation of jelly referred as guava leaf extract jelly (GJ). The proximate analysis of GJ was carried out according to the standard protocols with reference to the control jelly $(\mathrm{CJ})$ which was prepared without the addition of the extract. The carbohydrate content $(\mathrm{g} / 100 \mathrm{~g})$ of the two jellies was found to be similar as equal quantity of sugar has been added to the jellies (Table 3). Besides, the energy of GJ was found to be slightly higher $(120.6 \pm 1.20 \mathrm{kcal})$ than that of CJ $(105.6 \pm 1.50 \mathrm{kcal})$. There was no significant difference in the protein $(2.8 \pm 0.25$ and $3.0 \pm 0.19)$, fat $(0.16 \pm 0.02$ and $0.20 \pm 0.04 \mathrm{~g} / 100 \mathrm{~g})$ and vitamin contents in both the jellies.

\section{Physicochemical analysis of jellies}

The soluble solids content, acidity and viscosity are the three main characteristics used for the evaluation of internal quality of the processed foods such as jellies and determinate their ultimate destination. The average TSS values for GJ and CJ were found to be $65.5^{\circ}$ Brix and $65^{\circ}$ Brix respectively. The jelly was found to be clear without the formation of lumps which infers that the straining process was done perfectly. Further, $\mathrm{pH}$ of the two jellies CJ and GJ was observed to be $3.72 \pm 0.04$ and

Table 3 Proximate and nutritional analyses of jellies

\begin{tabular}{lrr}
\hline Nutrition composition & CJ (100 g) & GJ (100 g) \\
\hline pH & $3.72 \pm 0.04$ & $3.50 \pm 0.02$ \\
Moisture (\%) & $44.25 \pm 0.33$ & $45.05 \pm 0.25$ \\
Dry matter (\%) & $55.02 \pm 0.40$ & $54.00 \pm 0.25$ \\
Ash (\%) & $0.50 \pm 0.10$ & $0.59 \pm 0.20$ \\
Energy (kcal) & $105.6 \pm 1.50$ & $120.6 \pm 1.20$ \\
Carbohydrate (g/100 g) & $46.05 \pm 0.25$ & $45.78 \pm 0.25$ \\
Protein (g/100 g) & $2.8 \pm 0.25$ & $3.0 \pm 0.19$ \\
Fat (g/100 g) & $0.16 \pm 0.02$ & $0.20 \pm 0.04$ \\
Vitamin C (mg/100 g) & $6.24 \pm 0.13$ & $6.15 \pm 0.20$ \\
Vitamin B3 (mg/100 g) & $2.80 \pm 0.35$ & $2.90 \pm 0.75$ \\
\hline
\end{tabular}

Data is expressed as mean \pm SD
$3.50 \pm 0.02$. The apparent viscosity of GJ was $286.45 \mathrm{~Pa} \mathrm{~s}$, and the quality of jelly formed was high because of perfect gel formation, whereas for CJ apparent viscosity was 255.97 Pa s (Fig. 2).

\section{Texture analysis of jellies}

The textural analysis of the prepared jellies GJ and CJ has been carried out by measuring their firmness, cohesiveness, chewiness, springiness and gumminess. The firmness of GJ and CJ was found to be $194 \pm 12 \mathrm{~g}$ and $198 \pm 10 \mathrm{~g}$ whereas, the cohesiveness value of GJ and CJ was $0.74 \pm 0.04$ and $0.76 \pm 0.05$ respectively. Besides, the chewiness of GJ and CJ was observed to be $15.0 \pm 1.0 \mathrm{~mJ}$ and $15.5 \pm 1.5 \mathrm{~mJ}$, which are in close proximity to one another. Moreover, both the jellies GJ and CJ have exhibited nearly similar springiness i.e., $9.46 \pm 0.5 \mathrm{~mm}$ and $9.04 \pm 0.9 \mathrm{~mm}$. Further, the gumminess of GJ $(125 \pm 9.6 \mathrm{~g})$ is slightly higher than that of $\mathrm{CJ}(114 \pm 5.2 \mathrm{~g})$.

\section{Antibacterial activity of jellies}

Antibacterial activity of the guava leaf extract and jellies were evaluated against Bacillus subtilis, Proteus vulgaris, Staphylococcus aureus and Streptococcus mutans. The highest and lowest inhibition zones formed due to antagonistic effect of guava leaf extract on Bacillus subtilis and Staphylococcus aureus was $14.1 \pm 0.02 \mathrm{~mm}$ and $13.6 \pm 0.01 \mathrm{~mm}$ respectively. Besides, the zone of inhibition of Staphylococcus mutants and Proteus vulgaris was observed to be $13.3 \pm 0.01 \mathrm{~mm}$ and $12.1 \pm 0.03 \mathrm{~mm}$, respectively. Similar trend was observed with the jelly samples also (Table 4).

\section{Antioxidant activity of jellies against DPPH and hydroxyl radical}

Antioxidant activity of guava leaf extract and jellies (C) and GJ) were tested against hydroxyl radical $(* \mathrm{OH})$ and DPPH radical as shown in Table 4. Guava leaf extract was

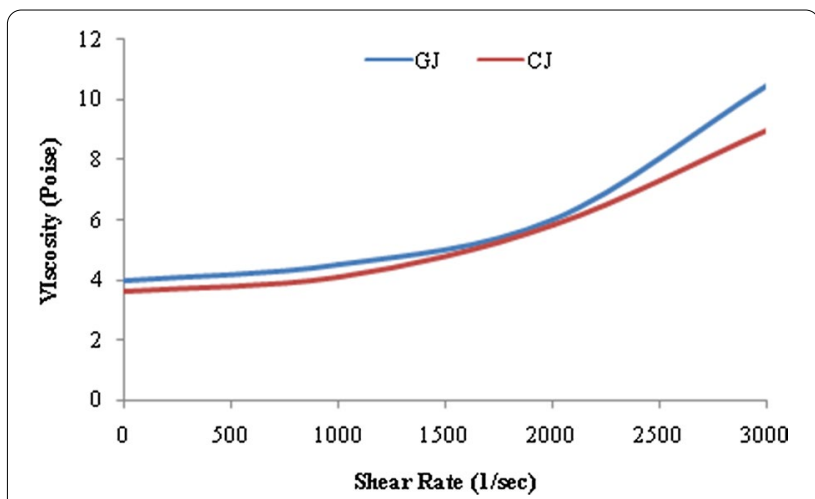

Fig. 2 Viscosity of guava leaf extract jelly and control jelly as a function of shear rate 
Table 4 Comparison of textural properties of guava leaf extract jelly (GJ) and control jelly (CJ)

\begin{tabular}{|c|c|c|c|c|c|}
\hline \multirow[t]{2}{*}{ Sample } & \multicolumn{5}{|l|}{ Parameters } \\
\hline & Firmness (g) & Cohesiveness & Chewiness (mJ) & Springiness (mm) & Gumminess (g) \\
\hline GJ & $194 \pm 12$ & $0.74 \pm 0.04$ & $15.0 \pm 1.0$ & $9.46 \pm 0.5$ & $125 \pm 9.6$ \\
\hline CJ & $198 \pm 10$ & $0.76 \pm 0.05$ & $15.5 \pm 1.5$ & $9.04 \pm 0.9$ & $114 \pm 5.2$ \\
\hline
\end{tabular}

Data is expressed as mean $\pm S D$

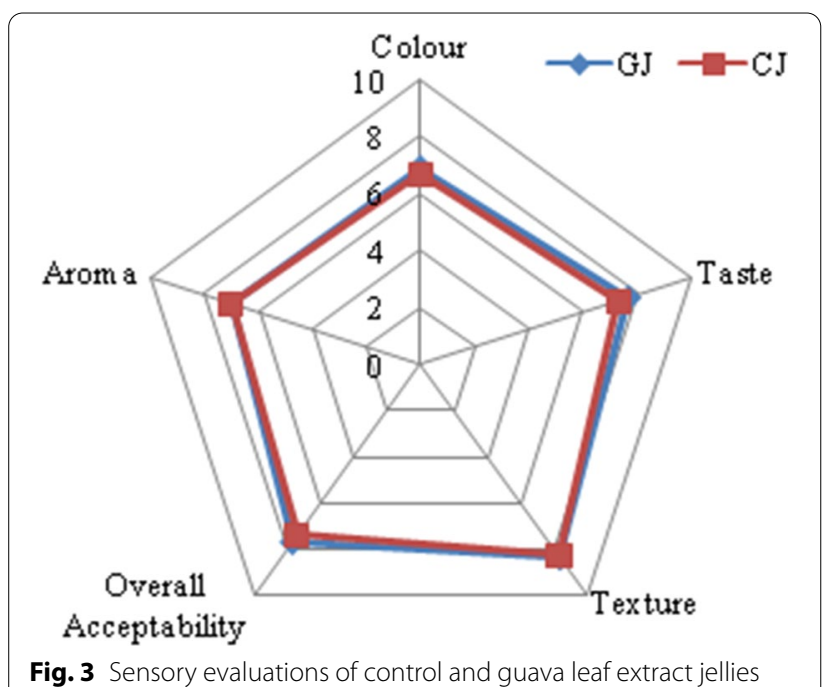

successful in scavenging DPPH* with $47.87 \%$ and $43.36 \%$ activity against "OH species. The IC50 value to guava leaf extract against DPPH radical was $62.7 \mu \mathrm{g} / \mu \mathrm{L}$. Upon testing the jellies, GJ was found to scavenge both the free radicals with efficiency of $42.38 \%$ and $33.45 \%$ respectively. Thus, the results corroborate the antioxidant properties in the jelly.

\section{Sensory evaluation of jellies}

The sensory attributes viz., colour, texture, taste, aroma and overall acceptability of two jellies, GJ and CJ were evaluated by serving the jellies to panelists who have assigned scores following the hedonic scale from 1 to 9. Both the jellies were pale in colour with smooth texture. The score for colour of CJ and GJ was $6.7 \pm 0.47$ and $6.95 \pm 0.69$ respectively, whereas the score for taste was $7.3 \pm 0.47$ and $7.7 \pm 0.86$, respectively. CJ was sweet in taste and the GJ is moderately bitter and sour in taste. The score for texture CJ and GJ was $8.26 \pm 0.64$ and $8.35 \pm 0.49$, respectively while; the score for aroma was 7.0 for both the jellies. Besides, the overall acceptability was $7.42 \pm 0.25$ and $7.66 \pm 0.47$ respectively for CJ and GJ (Fig. 3). GJ is rich in bioactive compounds having antioxidant and antimicrobial activities.

\section{Discussion}

The aqueous extract of guava leaves was screened for the presence of phytochemicals such as glycosides, flavonoids, saponins, polyphenols, terpenoids and tannins on qualitative basis. The extract was found to contain all the tested bioactive components (Table 1). Altemimi et al. (2017) also reported similarly about the presence of terpenoids, phenol and carbohydrates in the aqueous extract of guava leaves. The phytochemicals are found to possess various physiological activities, for instance, flavonoids are hydroxylated polyphenolic compounds produced against microbial infection in the plants in addition to antioxidant properties (Górniak et al. 2019). Similarly, saponins and tannins are found to possess inhibitory effect against certain gram positive bacteria that include Staphylococcus aureus and Bacillus cereus (Biswas et al. 2013).

Further, the guava leaf extract was subjected to negative mode mass spectroscopy that provides information about molecular structure of organic and inorganic compounds. Sugar and sugar alcohols, structure of glycosides, flavonoids, anthraquinones, aromatics, coumarin, isoflavonoids, cardenolides and triterpenes are generally detected using mass spectroscopy (Feil and Lun 2018). The mass spectrometry analysis of guava leaf extract confirms the presence of quercetin, gallocatechin, esculin, 3-sinapoylquinic acid, ellagic acid, gallic acid and citric acid that have several medicinal properties (Fig. 1; Table 2). Quercetin is involved in decreasing the mortality from heart disease besides exhibiting hypocholesterolemic and antioxidant activities (Sharma and Gupta 2010). Gallic acid inhibits pancreatic cholesterol esterase, which decreases cholesterol levels whereas, catechins are important as a preventive treatment for diabetes type 2 and obesity (Nayeem et al. 2016; Legeay et al. 2015). Ellagic acid prevents cancer and treats several viral and bacterial infections, while esculin acts as vasoprotective agent (Nayeem et al. 2016; Wang et al. 2013).

The bioactive compounds extracted from guava leaf have been used in the preparation of jelly referred as guava leaf extract jelly (GJ) and its proximate analysis was carried out in reference to the control jelly (CJ) which was prepared without guava leaf extract. The moisture, ash, carbohydrate, protein and vitamin $\mathrm{C}$ 
contents of GJ and CJ was found to be in the range of $44.25-45.05 \%, 0.50-0.59 \%, 45.78-46.05 \%, 2.8-3.0 \%$ and $6.15-6.24 \mathrm{mg} / 100 \mathrm{~g}$ respectively (Table 3 ). Similar trend was reported in case of red guava jams (Nissa et al. 2019). The moisture, ash, carbohydrate, protein and vitamin $\mathrm{C}$ contents in the jelly developed from varieties of guava were in the range of $33-38.5 \%, 0.08-0.19 \%, 61-66 \%$, $0.02-0.04 \%, 7-11 \mathrm{mg} / 100 \mathrm{~g}$ (Joshi et al. 2017). Water-soluble vitamins ( $B$ and $C$ ) are not stored by the body since they are eliminated in urine and hence humans require their continuous supply in diet. Hence, adequate intake of these jellies will definitely help the consumer by lowering high cholesterol levels in the body and boost up their immunity.

Physicochemical analysis of the prepared jellies GJ and CJ was carried out to evaluate their internal quality. TSS explains the presence of high concentration of pectin which improves the solid holding capacity. The average TSS values for GJ and CJ were found to be $65.5^{\circ}$ Brix and $65^{\circ}$ Brix respectively, which were in the ideal range (65$70^{\circ}$ Brix) for jelly (Sharma et al. 2011). Similarly, $\mathrm{pH}$ plays a prominent role in the gel firmness besides the pectin content in the jelly, because low $\mathrm{pH}$ increases the rigidity by enhancing the interactions between polymer to polymer than polymer to water (Seshadri et al. 2019). On the other hand, the higher $\mathrm{pH}$ contributes to the browning reaction during preparation and predominantly dissociates the carboxyl groups leading to alterations in the shape (Shinwari and Rao 2018).

Owing to semisolid nature, jellies exhibit both viscosity and elasticity properties and measure of these rheological properties are essential to assess the quality of the processed foods. The carbohydrates and acid which are used as ingredients in jelly preparation are responsible for enhancing the viscous nature besides improving the gel forming structure, consistency and the shelf life. The experimental analysis performed on GJ and CJ, showed that the viscosity decreases with rise in shear, which results in reorganization of the structure at larger shear forces. The apparent viscosity of GJ was $286.45 \mathrm{~Pa}$ s, and the quality of jelly formed was high because of perfect gel formation, where as for CJ apparent viscosity was
255.97 $\mathrm{Pa}$ s. As both the jellies have the same concentration of sugar and other ingredients except guava leaf extract in GJ, the viscosities of both the jellies are in close proximity with each other. Xiu et al. (2011) observed that different concentrations of the jellies exhibit different viscosities because of inter-molecular forces between molecules and water solute interactions. The jelly was of visco-elastic nature and from the available results it can be concluded that the GJ will follow the Herschel-Bulkley model of viscoplastic fluid (Fig. 2).

Texture analysis represents mastication operation and the parameters emphasized during the analysis are firmness, cohesiveness, chewiness, springiness and gumminess of jellies (Table 5). Concentrations of sugar and pectin have profound influence on the textural properties of prepared jellies (Royer et al. 2006). Besides sugar and pectin, $\mathrm{pH}$ also influences the firmness of the jelly which is prepared with $45 \%$ sugar. The firmness of GJ and CJ was found to be $194 \pm 12 \mathrm{~g}$ and $198 \pm 10 \mathrm{~g}$ respectively inferring no significant difference between the jellies. In addition, cohesiveness of product indicates rate of material deformation under mechanical enforcement. Cohesiveness is measure of the strength of internal structure and difficulty in breaking down the internal bonds (Hamedi et al. 2018). The cohesiveness value of GJ $(0.74 \pm 0.04)$, confirms that the jelly is easy to chew and swallow. Apart from the above mentioned properties, chewing is very important for the consumers' acceptance of the product. It corresponds to the energy required to masticate a solid food into ready for swallowing state (Calvarro et al. 2016). The chewiness of GJ and CJ were observed to $15.0 \pm 1.0 \mathrm{~mJ}$ and $15.5 \pm 1.5 \mathrm{~mJ}$ respectively which are in close proximity to one another.

Another important criterion that needs to be studied in jelly samples is springiness which is inversely proportional to hardness (Kreungngern and Chaikham 2016). Both the jellies GJ and CJ have exhibited nearly similar springiness i.e., $9.46 \pm 0.5 \mathrm{~mm}$ and $9.04 \pm 0.9 \mathrm{~mm}$ respectively. It represents the rate at which the deformed sample regains its initial condition upon removal of the deforming force (Garrido et al. 2014). Springiness depends upon the concentration of the pectin used for jelly preparation

Table 5 Antibacterial and antioxidant activity of guava leaf extract and jellies

\begin{tabular}{|c|c|c|c|c|c|c|}
\hline \multirow[t]{2}{*}{ Samples } & \multicolumn{4}{|c|}{ Antibacterial activity-zone of inhibition (mm) } & \multicolumn{2}{|c|}{ Antioxidant activity (\%) } \\
\hline & P. vulgaris & S. mutans & B. subtilis & S. aureus & DPPH radical & Hydroxyl radical \\
\hline Guava leaf extract & $12.1 \pm 0.03$ & $13.3 \pm 0.01$ & $14.1 \pm 0.02$ & $13.6 \pm 0.01$ & $47.87 \pm 0.07$ & $43.36 \pm 0.06$ \\
\hline Ampicillin & $03.3 \pm 0.01$ & $14.7 \pm 0.05$ & $13.6 \pm 0.01$ & $15.8 \pm 0.04$ & - & - \\
\hline Control jelly (CJ) & $03.1 \pm 0.04$ & $07.2 \pm 0.01$ & $05.2 \pm 0.02$ & $07.7 \pm 0.03$ & $26.23 \pm 0.04$ & $20.08 \pm 0.05$ \\
\hline Guava jelly (GJ) & $11.4 \pm 0.06$ & $12.9 \pm 0.01$ & $13.6 \pm 0.07$ & $13.1 \pm 0.03$ & $42.38 \pm 0.06$ & $33.44 \pm 0.04$ \\
\hline
\end{tabular}

Data is expressed as mean \pm standard deviation 
(Hamedi et al. 2018). Since the concentration of pectin used in this study is same in both jellies, the springiness results are similar for both the jellies.

Besides the mentioned properties, gumminess of the jellies was calculated as the product of hardness times cohesiveness. Gumminess of GJ (125 $\pm 9.6 \mathrm{~g})$ is slightly higher than that of CJ $(114 \pm 5.2 \mathrm{~g})$. The gumminess of a jelly increases with increase in hardness as the energy needed to disintegrate the jelly increases substantially (Mutlu et al. 2018). From the results of texture analysis, it was observed that both the control and the guava extract jellies shared similar properties indicating that, the addition of guava extract does not bring any change in the texture properties of jelly. Moreover, addition of guava leaf extract enriches the jelly with secondary metabolites exhibiting bioactive properties. Secondary metabolites are non-nutritive molecules produced by plants for the sake of their own protection, which were found to possess similar or different effect on humans against various diseases and disorders (Slavin et al. 2017).

The antibacterial activity of guava leaf extract was assessed against four tested bacteria viz., Bacillus subtilis, Proteus vulgaris, Staphylococcus aureus and Streptococcus mutans. These bacteria are mostly responsible for causing food spoilage and foodborne diseases which lead towards increased morbidity and mortality (Liu et al. 2017). For instance, B. subtilis causes food borne illness by producing heat stable toxin, amylopsin. Similarly, Staphylococcus strains cause food poisoning by producing enterotoxins which are responsible for vomiting, diarrhea and in extreme cases it will cause the consumer to collapse. Such unfortunate situations can be overcome in the jelly (GJ) due to the presence of guava leaf extract with antibacterial activity. Least activity was found in Proteus vulgaris, due to the presence of thick cell wall made up of lipopolysaccharides that can effectively prevent the passage of leaf extracts (Slavin et al. 2017). Whereas, Bacillus subtilis, Staphylococcus aureus and Streptococcus mutans have a web like cell wall made of peptidoglycan layer, which is comparatively permeable to leaf extracts (Bai et al. 2016). It was reported that nearly $39 \%$ of the children consume jams and jellies regularly (Iftikhar et al. 2012). Because of the sticky and sugary nature of jelly, it is predominantly responsible for tooth decay. Bearing this in mind, we attempted to add guava leaf extract possessing antibacterial activity to the jelly which has potential to control the bacterial growth in the mouth. The results shown in the Table 4 authenticates the antibacterial nature of guava leaf extract and the jelly prepared using it as an ingredient.

Antioxidant properties are considered as crucial for food and food supplements these days because free radicals excessively produced inside the body/cell are capable of causing various diseases such as cancer, cardio vascular diseases, neurodegenerative disease etc. (Zhang et al. 2015). In this work, ESR spectroscopy is used to check the activity instead of UV-Vis spectrophotometer because, ESR is considered as one of the most sensitive, direct and effective methods to detect antioxidant activity of biological samples (Kumar et al. 2011). Guava leaf extract was successful in scavenging $\mathrm{DPPH}^{*}$ with $47.87 \%$ and $43.36 \%$ activity against ${ }^{*} \mathrm{OH}$ species. This might be due to the presence of compounds like quercetin, myricetin (phenolic compounds) etc., which are known for their therapeutic value with rich antioxidant properties (Chiari-Andreo et al. 2017). Diaz-de-Cerio et al. (2016) has confirmed the same by screening compounds using HPLC as well as elaborated their beneficial effects on various chronic diseases. As antioxidants reduce the oxidative stress and allied diseases, the consumption of GJ can substantially reduce the incidence of these diseases because of its antioxidant properties.

The sensory evaluation of prepared jellies corroborated the acceptability of GJ owing to its appealing colour, smooth texture and good taste (Fig. 3). The prepared product, GJ is having better nutritional value needed for human growth and hence, its consumption adds benefits to the consumers. Moreover, the jellies are consumed by the people of all the ages and thus there is a huge market potential. In order to scale up the jelly production, one should be assured about the abundant availability of the guava leaf as well as conduct optimization studies to obtain high yield of product with uniform quality and texture at every batch of production.

\section{Acknowledgements}

The authors are grateful to Management, VFSTR, India and Director, ICAR-IISS, Mau for extending their kind support.

\section{Authors' contributions}

NSSK: investigation (lead), Writing-original draft (equal); NMS: curation (equal); SSR: curation (equal); ADC: conceptualization (lead), writing-original draft (equal); SP: investigation (equal) ISK: methodology (supporting); SPJK: Resource (supporting); BSA: methodology (supporting); VRD: visualization (supporting), writing original draft (supporting). All authors read and approved the final manuscript.

\section{Funding}

No financial assistance was received either from government or any private agency for the present work.

\section{Availability of dat and materials}

The data that support the findings of this study are available on request from the corresponding author. The data are not publicly available due to privacy or ethical restrictions.

\section{Ethics approval and consent to participate}

This article does not contain any studies with human or animal subjects.

\section{Competing interests}

The authors declare that they have no conflicts of interest with respect to the work described in this manuscript. 


\begin{abstract}
Author details
1 Department of Biotechnology, Vignan's Foundation for Science, Technology and Research, Vadlamudi, Andhra Pradesh 522213, India. ${ }^{2}$ Faculty of Fisheries and Food Science, Universiti Malaysia Terengganu, 21030 Kuala Terengganu, Terengganu, Malaysia. ${ }^{3}$ Division of Food Technology, Department of Chemical Engineering, Vignan's Foundation for Science, Technology and Research, Vadlamudi, Andhra Pradesh 522213, India. ${ }^{4}$ ICAR-Directorate of Floricultural Research, Pune, Maharashtra 411005, India. ${ }^{5}$ Department of Chemistry, Presidency College, Chennai 600005, India.
\end{abstract}

Received: 6 December 2020 Accepted: 15 February 2021

Published online: 01 March 2021

\section{References}

Altemimi A, Lakhssassi N, Baharlouei A, Watson DG, David A (2017) Lightfoot phytochemicals: extraction, isolation, and identification of bioactive compounds from plant extracts. Plants 6:42

AOAC (2008) Official methods of analysis, 2nd revision, 18th edn. Association of official analytical chemists, Maryland

Bai L, Takagi S, Ando T, Yoneyama H, Ito K, Mizugai H, Isogai E (2016) Antimicrobial activity of tea catechin against canine oral bacteria and the functional mechanisms. J Vet Sci 78(9):1439-1445

Biswas B, Rogers K, McLaughlin F, Daniels D, Yadav A (2013) Antimicrobial activities of leaf extracts of guava (Psidium guajava L.) on two gram-negative and gram-positive bacteria. Int J Microbiol 2013:746165-746467

Calvarro J, Perez-Palacios T, Ruiz J (2016) Modification of gelatin functionality for culinary applications by using transglutaminase. Int J Gastron Food Sci 5:27-32

Chiari-Andreo BG, Trovatti E, Marto J, Almeida-Cincotto MGJ, Melero A, Corrêa MA, Chiavacci LA, Ribeiro H, Garrigues T, Isaac VLB (2017) Guava: phytochemical composition of a potential source of antioxidants for cosmetic and/or dermatological applications. Braz J Pharm Sci 53:16141

Diaz-de-Cerio E, Gomez-Caravaca AM, Verardo V, Fernandez-Gutierrez A, SeguraCarretero A (2016) Determination of guava (Psidium Guajava L.) leaf phenolic compounds using HPLC-DAD-QTOF-MS. J Funct Foods 22:376-388

Evans WC (1997) An index of medicinal plants. Textb Pharmacogn 7:12-14

Feil R, Lunn JE (2018) Quantification of soluble sugars and sugar alcohols by LC-MS/MS. Plant Metabolomics 1778:87-100

García-Nino WR, Zazueta C (2015) Ellagic acid: pharmacological activities and molecular mechanisms involved in liver protection. Pharmacol Res 97:84-103

Garrido Jl, Lozano JE, Genovese DB (2014) Effect of formulation variables on rheology, texture, colour, and acceptability of apple jelly: modelling and optimization. LWT Food Sci Technol 62(1):325-332

Ghosh P, Pradhan RC, Mishra S, Patel AS, Kar A (2017) Physicochemical and nutritional characterization of Jamun (Syzygium cuminii). Curr Res Nutr Food Sci 5(1):25-35

Górniak I, Bartoszewski R, Króliczewski J (2019) Comprehensive review of antimicrobial activities of plant flavonoids. Phytochem Rev 18(1):241-272

Gutiérrez-Grijalva E, Picos SM, Leyva LN, Criollo MM, Vazquez OG, Heredia J (2018) Flavonoids and phenolic acids from Oregano: occurrence, biological activity and health benefits. Plants 7:2

Guntur SR, Kumar NSS, Manasa MH, Vijaya RD (2018) In vitro studies of the antimicrobial and free-radical scavenging potentials of silver nanoparticles biosynthesized from the extract of Desmostachya bipinnata. Anal Chem Insights 13:1177390118782877

Hamedi F, Mohebbi M, Shahidi F, Azarpazhooh E (2018) Ultrasound assisted osmotic treatment of model food impregnated with pomegranate peel phenolic compounds: mass transfer, texture, and phenolic evaluations. Food Bioprocess Technol 11(5):1061-1074

Horticultural Statistics at a Glance (2018) http://agricoop.nic.in/sites/default/ files/horticulture\%20Statistics\%20at\%20a\%20Glance-2018.pdf. Accessed 9 Apr 2020

Iftikhar A, Zafar M, Kalar MU (2012) The relationship between snacking habits and dental caries in school children. Int J Collab Res Intern Med Public Health 4(12):1943-1951

Jacob S, Chintagunta AD, Banerjee R (2016) Selective digestion of industrial potato wastes for efficient biomethanation: a sustainable solution for safe environmental disposal. Int J Sci Environ Technol 13:2363-2374
Joshi H, Kochhar A, Boora RS (2017) Organoleptic and nutritional evaluation of value added products developed from new varieties of white and pinkfleshed guavas. Chem Sci Rev Lett 6(24):2108-2113

Keshani S, Luqman Chuah A, Russly AR (2012) Effect of temperature and concentration onnrheological properties pomelo juice concentrates. Int Food Res J 19(2):553-562

Kokate CK (1999) Phytochemical methods. Phytotherapy 78:126-129

Kreungngern D, Chaikham P (2016) Rheological, physical and sensory attributes of Chao Kuay jelly added with gelling agents. Int Food Res J 23(4):1474-1478

Kumar NSS, Nazeer RA, Jaiganesh R (2011) Purification and biochemical characterization of antioxidant peptide from horse mackerel (Magalaspis cordyla) viscera protein. Peptides 32:1496-1501

Kumari UK, Rishitha G, Prasad KR, Kumar PS (2017) Value added products of guava. Agric Update 12:2171-2177

Legeay S, Rodier M, Fillon L, Faure S, Clere N (2015) Epigallocatechin gallate: a review of its beneficial properties to prevent metabolic syndrome. Nutrients 7:5443-5468

Liu Q, Meng X, Li Y, Zhao CN, Tang GY, Li HB (2017) Antibacterial and antifungal activities of spices. Int J Mol Sci 18(6):1283

Mutlu C, Tontul SA, Erbaş M (2018) Production of a minimally processed jelly candy for children using honey instead of sugar. LWT Food Sci Technol 93:499-505

Nayeem N, Asdaq SMB, Heba S, Ahel-Alfqy S (2016) Gallic acid: a promising lead molecule for drug development. J Appl Pharm 8(2):1-4

Nazeer RA, Divya Prabha KR, Sampath Kumar NS, Jai Ganesh R (2013) Isolation of antioxidant peptides from clam, Meretrix casta (Chemnitz). J Food Sci Technol 50(4):777-783

Nissa C, Arifan F, Febrianto R, Aditya W, Dwimawanti DH, Widyasmara RP (2019) Effect of sugar on nutrient composition and shelf life of red guava jams. IOP Conf Ser Earth Environ Sci 406:012027

Reddy JJ, Chowdary MK, Kumar TS, Kumar NSS, Krupanidhi S, Ramu DV (2015) Development and quality assessment of fish flavored potato chips and its consumer acceptance. Res J Pharm Biol Chem 6:770-774

Royer G, Madieta E, Symoneaux R, Jourjon F (2006) Preliminary study of the production of apple pomace and quince jelly. Food Sci Technol 39:1022-1025

Seshadri S, Manoharan S, Singh HS (2019) Preventive regulation of jelly seed disorder in 'amrapali' mango (Mangifera indica) by preharvest spray. Hortic Plant J 5:70-78

Singh RP, Chintagunta AD, Agarwal DK, Kureel RS, Kumar SJ (2019) Varietal replacement rate: prospects and challenges for global food security. Glob Food Secur 2019:100324

Sharma A, Gupta H (2010) Quercetin-a flavanoid. Chron Young Sci 1:10-15

Sharma R, Joshi V, Rana J (2011) Nutritional composition and processed products of quince (Cydonia oblonga Mill.). Indian J Nat Prod Resour 2(3):354-357

Shaheena S, Chintagunta AD, Dirisala VR, Kumar NSS (2019) Extraction of bioactive compounds from Psidium guajava and their application in dentistry. AMB Express 9(1):208

Shinwari KJ, Rao PS (2018) Stability of bioactive compounds in fruit jam and jelly during processing and storage: a review. Trends Food Sci Technol 75:181-193

Slavin YN, Asnis J, Häfeli UO, Bach H (2017) Metal nanoparticles: understanding the mechanisms behind antibacterial activity. J Nanobiotechnol 15(1):65

Wang Y, Chantreau M, Sibout R, Hawkins S (2013) Plant cell wall lignification and monolignol metabolism. Front Plant Sci 4:220

Watts BM, Ylimaki GL, Jeffery LE, Elias LG (1989) Basic sensory methods for food evaluation. International Development Research Centre, Ottawa

Xiu A, Zhou M, Zhu B, Wang S, Zhang J (2011) Rheological properties of salecan as a new source of thickening agent. Food Hydrocoll 25:1719-1725

Zhang YJ, Gan RY, Li S, Zhou Y, Li AN, Xu DP, Li HB (2015) Antioxidant phytochemicals for the prevention and treatment of chronic diseases. Molecules 20(12):21138-21156

\section{Publisher's note}

Springer Nature remains neutral with regard to jurisdictional claims in published maps and institutional affiliations. 